\title{
Small area deprivation and stigmatising attitudes towards mental illness: a multilevel analysis of Health Survey for England (2014) data
}

\author{
Elizabeth Ingram ${ }^{1} \mathbb{D} \cdot$ Rebecca Jones $^{1} \cdot$ Peter Schofield $^{2} \cdot$ Claire Henderson $^{3}$
}

Received: 9 January 2019 / Accepted: 25 April 2019 / Published online: 4 May 2019

(c) The Author(s) 2019

\begin{abstract}
Purpose The aim of this study was to explore how small area deprivation is associated with attitudes towards mental illness in a large sample of individuals living in private households in England.

Method Cross-sectional data from Health Survey for England (2014) were analysed using multilevel models. The exposure of interest was the deprivation level of the small area in which an individual resides as measured by Index of Multiple Deprivation (IMD) score. The primary outcome was an individual's overall attitude towards mental illness, measured using a 12 item version of the Community Attitudes toward the Mentally Ill (CAMI) scale. Further outcomes were the two subscales of the CAMI, reflecting attitudes of (1) prejudice and exclusion and (2) tolerance and support. Individuals were nested within household and small geographical area.

Results 5820 participants were included. Results from unadjusted models found strong evidence that individuals residing in the most deprived areas of England have worse attitudes towards mental illness compared to individuals living in the least deprived areas (estimated difference $=-3.5$ points; $95 \% \mathrm{CI}-4.8$ to $-2.2 ; P<0.001$ ). After adjusting for age, sex, education level, ethnicity and weekly income there was no longer evidence for this association (adjusted difference $=-0.1$ points, $95 \%$ CI -1.3 to $1.2 ; P=0.931)$. Similar patterns of results were found for the CAMI subscales.

Conclusions The relationship between small area-level deprivation and attitudes towards mental illness is no longer observed when controlling for certain individual-level characteristics.
\end{abstract}

Keywords Stigma $\cdot$ Attitudes $\cdot$ Mental illness $\cdot$ Neighbourhood deprivation $\cdot$ Multilevel modelling

\section{Introduction}

Each year approximately one in six adults in England experience a common mental disorder (CMD) such as depression or anxiety [1]. However, despite the frequency of mental

Electronic supplementary material The online version of this article (https://doi.org/10.1007/s00127-019-01722-w) contains supplementary material, which is available to authorized users.

Elizabeth Ingram

e.ingram.17@ucl.ac.uk

1 Division of Psychiatry, University College London, Maple House, 149 Tottenham Court Rd, London, UK

2 School of Population Health \& Environmental Sciences, Faculty of Life Sciences and Medicine, King's College London, Addison House, Guy's Campus, London, UK

3 Department of Health Service and Population Research, Institute of Psychiatry, Psychology and Neuroscience, King's College London, De Crespigny Park, London, UK illness, levels of stigma and discrimination remain high [2]. This can adversely affect outcomes. Stigma is one of the biggest factors contributing to reduced help-seeking for mental illnesses [3] and stigma towards CMDs can negatively impact quality of life [2] and is associated with both increased absenteeism and lost productivity in the workplace [4].

In relation to mental illness, stigma can be defined as problems with attitudes (prejudice), knowledge (ignorance) or behaviour (discrimination) towards an individual with a mental health problem [5], where discrimination is the behavioural responses that arise as a result of stigma [6]. Due to its adverse effects, identifying and addressing the causes of stigmatising attitudes towards mental illness are a priority for policy makers, health services and researchers alike.

Previous research has highlighted that individual characteristics such as age [7, 8], sex [7-11], ethnicity [7] and familiarity with mental illness $[7,8,12,13]$ are associated 
with attitudes towards mental illness. For example, younger and older populations (between 16 and 35 years and over 65 years, respectively) hold the most negative views whilst women hold more positive attitudes compared to men in most studies exploring gender differences [7-10]. White respondents give scores indicating more positive views compared to respondents from black and minority ethnic groups [7] and those suffering from a mental illness, or who know an individual that is, hold more positive attitudes $[7,8,12$, 13]. In addition, evidence suggests an individual's socioeconomic status (SES) [7], and markers of SES such as education level, employment status and household income, are associated with attitudes towards mental illness [8]. For example, unemployed participants from low SES groups, with no qualifications or low household incomes report the least positive views [8].

Findings also suggest differences in the areas in which individuals reside are associated with their attitudes towards mental illness. Previous work on area-level differences comes from the National Centre of Social Research (NatCen) and suggests respondents living in the most deprived areas of England report the least positive views [8]. This research used Index of Multiple Deprivation (IMD) scores to account for different dimensions of possible small area deprivation by combining seven domains: income deprivation; employment deprivation; health deprivation and disability; education, skills and training deprivation; barriers to housing and services; crime; and living environment deprivation [14]. However, whilst NatCen's findings were age-standardised and conducted separately for men and women, their analyses did not control for certain individual-level characteristics associated with stigmatising attitudes and potentially associated with area deprivation (income and ethnicity for example). They also did not account for how attitudes may be clustered within households and areas, a limitation given that those we communicate with can greatly mould our beliefs and attitudes [15]. More recent work demonstrates the importance of accounting for differences in individual characteristics when exploring regional differences in stigmatising attitudes [16]. However, this work used nine large regions of England, such as the North West and South East, to define areas. Large areas such as these may contain a range of area types within them that differ markedly in deprivation levels and, in turn, in the attitudes of residents.

This present study aims to explore how small area deprivation is associated with individual attitudes towards mental illness in a large sample of individuals living in private households in England. Using multilevel modelling techniques, we have been able to account for any clustering of attitudes within areas and household. This study also accounts for differences in certain individual characteristics that may explain previously seen associations between area deprivation and attitudes. Understanding how different factors, operating at different levels, are associated with attitudes towards mental illness may help local governments and others to better focus public health initiatives that aim to reduce stigma, maximising their impact and effectiveness.

\section{Methods}

\section{Participants}

This study uses data from Health Survey for England (HSE) (2014) [17]. HSE is a series of annual, household surveys that gather cross-sectional data at the household and individual level. The survey includes two interviews: an initial interview which may then be followed by a nurse visit. Both interviews include core questions that are the same each year plus year-specific questions that focus on particular topics. In 2014, one topic of focus was mental health. HSE uses a multi-stage stratified random probability sampling method to obtain a sample representative of the population living in private households in England [18]. A random sample of primary sampling units (PSUs) is selected from a small user Postcode Address File (PAF) based on postcode sector. A random sample of postal addresses is then selected from each PSU. Further details of HSE procedures can be found elsewhere [18].

In HSE (2014) response rates for the interview and nurse visit were $55 \%$ and $37 \%$, respectively. This present study included participants aged 16 years and over with complete data on attitudes towards mental illness, ethnicity, highest educational attainment and weekly income.

\section{Measures}

\section{Outcome measures: attitudes towards mental illness}

In the initial interview of HSE (2014) participants aged 16 years and over were asked about their attitudes towards mental illness using a 12 -item version of the 40 -item Community Attitudes toward the Mentally Ill (CAMI) scale [19]. Prior to the survey, NatCen conducted an exploratory factor analysis of the 12 CAMI items, revealing subscales that reflect two themes in attitudes towards mental illness: (1) prejudice and exclusion; and (2) tolerance and support for community care [8] (Online Resource 1). Both subscales have been shown to be internally reliable with a Cronbach's $\alpha$ score of 0.767 for prejudice and exclusion and 0.668 for tolerance and support $[8,20]$.

In this study, participants rated the extent to which they agree with the 12 CAMI statements on a 5-point Likert scale (agree strongly to strongly disagree). There was also a sixth response of 'Don't know' (Online Resource 1). Statements reflecting attitudes of tolerance and support 
were worded positively and agreement reflected more positive views, for example 'Virtually anyone can become mentally ill'. Statements reflecting views of prejudice and exclusion were worded negatively and agreement indicated more negative views, for example, 'People with mental illness don't deserve our sympathy'. For statements worded in a positive direction, responses were scored as following: agree strongly $=100$ points; agree slightly $=75$; neither agree nor disagree $=50$; disagree slightly $=25$; and disagree strongly $=0$ points. Negative statements were scored in the reverse order, creating scores ranging from 0 to 100 with higher scores representing more positive attitudes.

For each theme in attitudes, two scores were calculated for each participant by taking the mean average of their scores for each statement relating to that subscale. Those responding 'Don't know' to more than one out of six statements for each theme were excluded from this calculation. A single score reflecting each participant's overall attitude towards mental illness was derived by calculating the average of the two mean scores for each subscale.

The primary outcome of this study was an individual's overall attitude towards mental illness. Two further outcomes were (1) an individual's attitude towards mental illness reflecting views of prejudice and exclusion, and (2) an individual's attitude reflecting views of tolerance towards those with mental illness and support for community care.

\section{Main exposure: small area-level deprivation}

This study measures deprivation using the Index of Multiple Deprivation (IMD) score calculated for each household in the initial interview of HSE (2014) [18]. The IMD combines seven domains of area-level deprivation (detailed above) [14]. Each domain uses a combination of indicators to calculate the measure and domains are weighted to reflect their perceived importance [14]. Research supports the weights selected [21] and further details are found elsewhere [14]. Combining each measure creates a deprivation score for each small area in England, allowing areas to be compared based on their level of multiple deprivation rather than using a measure of equivalised household income. This study used IMD scores at the Lower Super Output Area (LSOA) level, as defined by the Office of National Statistics (ONS). LSOA areas have fixed boundaries and consistent populations (below thresholds of 3000 individuals and 1200 households). ONS redefines the boundaries for each national census, with the last revision in December 2011. HSE (2014) report IMD scores as quintiles. Since 2014 a new version of the IMD has been released, but the release date was too late for inclusion in the HSE (2014) report.

\section{Individual-level variables}

Several individual-level variables were included in this study. These were: (1) age (16-24, 25-34, 35-44, 45-54, 55-64, 65-74 and 75 + years) $[7,8]$; (2) sex (male and female) [7-11], (3) ethnicity (white, black, Asian and mixed/other) [7]; (4) closest person with a mental illness, as a marker of familiarity with mental illness (self, immediate family/partner, other family or friend, acquaintance, colleague or other, don't know anyone) [7, 8, 12, 13]; (5) highest educational attainment (no qualifications; post16 qualifications such as GCSEs; post-18 qualifications below degree level, including A Levels; and degree level qualifications or equivalent); (6) equivalised weekly income (£0-£233, £233-£369, £369-£532,£532-£852 and £852+); and (7) employment status (foreman or supervisor; manager; self-employed; or employee not elsewhere classified) [8]. Participants were asked about their familiarity with mental illness in the later conducted nurse visit using the following: "Who is the person closest to you who has or has had some kind of mental illness?" (taken from the 1994 Attitudes to Mental Illness Survey [22]). To measure individual income participants were allocated to their household weekly income, equivalised to account for the number of adults and dependent children in the household. Weekly income data are reported as quintiles.

\section{Statistical analysis}

We explored associations between small area-level deprivation and attitudes towards mental illness using multilevel linear regression modelling with random effects at local area (LSOA) and household levels to account for clustering within geographical areas and households. Firstly, an unadjusted model was fitted for each outcome to explore the association with small area-level deprivation ignoring potential confounding. Separate bivariable models were then fitted to adjust for each individual-level variable in turn. If changes to estimates for the association between area deprivation and attitudes were negligible when adjusting for an individuallevel variable it was not included in the final model. To build the final models for each outcome, age and sex were first added a priori. Individual-level variables found to change model estimates in bivariable analyses were then added in turn, starting with the variable resulting in the greatest change in estimates. Final models were reached when the addition of further variables no longer affected model estimates. Estimated mean differences in attitudes towards mental illness for difference levels of individual-level variables were also explored using univariable analyses.

We used tests for trend to investigate overall relationships between the level of local area deprivation and the three attitude outcomes. We estimated intra-class correlation 
coefficients (ICCs) to assess the proportion of the variance in attitudes at each of the three levels (individual, household and local area), and we performed likelihood ratio (LR) tests to examine whether final models with a random effect of household fitted the data as well as models with a random effect of both area and household. All analyses were unweighted and were conducted using STATA/SE 15.1. This research complies with the principles of the Declaration of Helsinki.

\section{Results}

In HSE (2014) 8077 adults (aged $\geq 16$ ) participated in the initial interview. Of these, $7032(87.1 \%)$ had complete data on attitudes towards mental illness. We initially conducted all analyses using the subsample of individuals with complete data on familiarity with mental illness $(N=4227)$ and employment status $(N=5539)$ to explore these variables as potential confounders or mediators. When it became clear that both variables did not change model estimates materially, analyses were repeated in the larger initial interview sample. 1212 participants ( $15.0 \%$ of the initial sample) with incomplete data on other variables of interest were excluded from analyses, leaving a final analytical sample of 5820 participants (72.1\% of those interviewed) (Fig. 1) nested within 3741 households and 2422 local areas (LSOAs). Table 1 shows the characteristics of the study sample and Table 2 shows estimated mean differences in attitudes towards mental illness for different levels of individual-level variables, including familiarity with mental illness and employment status.

\section{Overall attitudes towards mental illness}

Results of an unadjusted multilevel model accounting for clustering at household and area-levels found strong evidence of differences in attitudes towards mental health for different levels of local deprivation $\left(P_{\text {global }}<0.001\right)$. Individuals residing in the most deprived areas of England have worse overall attitudes towards mental illness when compared to individuals living in the least deprived areas (estimated difference $=-3.5$ points; $95 \% \mathrm{CI}-4.8$ to $-2.2 ; P<0.001)$. There was also strong evidence that individuals from increasingly more deprived local areas hold increasingly less positive attitudes towards mental illness $\left(P_{\text {trend }}<0.001\right.$; Table 3$)$. After adjusting for age and sex, strong evidence remained for an overall association between small area deprivation and overall attitudes $\left(P_{\text {global }}<0.001\right)$, with higher levels of deprivation associated with worse attitudes $\left(P_{\text {trend }}<0.001\right.$; Table 3$)$.

After adjustment for age, sex and education level, there was still evidence that participants residing in the most deprived areas of England have worse overall attitudes towards mental illness than those from the least deprived areas (adjusted difference $=-1.5$ points; $95 \% \mathrm{CI}-2.8$ to $-0.3 ; P=0.018)$. However, the magnitude of the estimated difference was reduced in comparison with the unadjusted difference. The analysis likewise still found evidence for an overall association $\left(P_{\text {global }}=0.012\right)$ and a trend in attitudes worsening with higher levels of deprivation $\left(P_{\text {trend }}=0.005\right)$,
Fig. 1 Selection of study participants, HSE (2014)

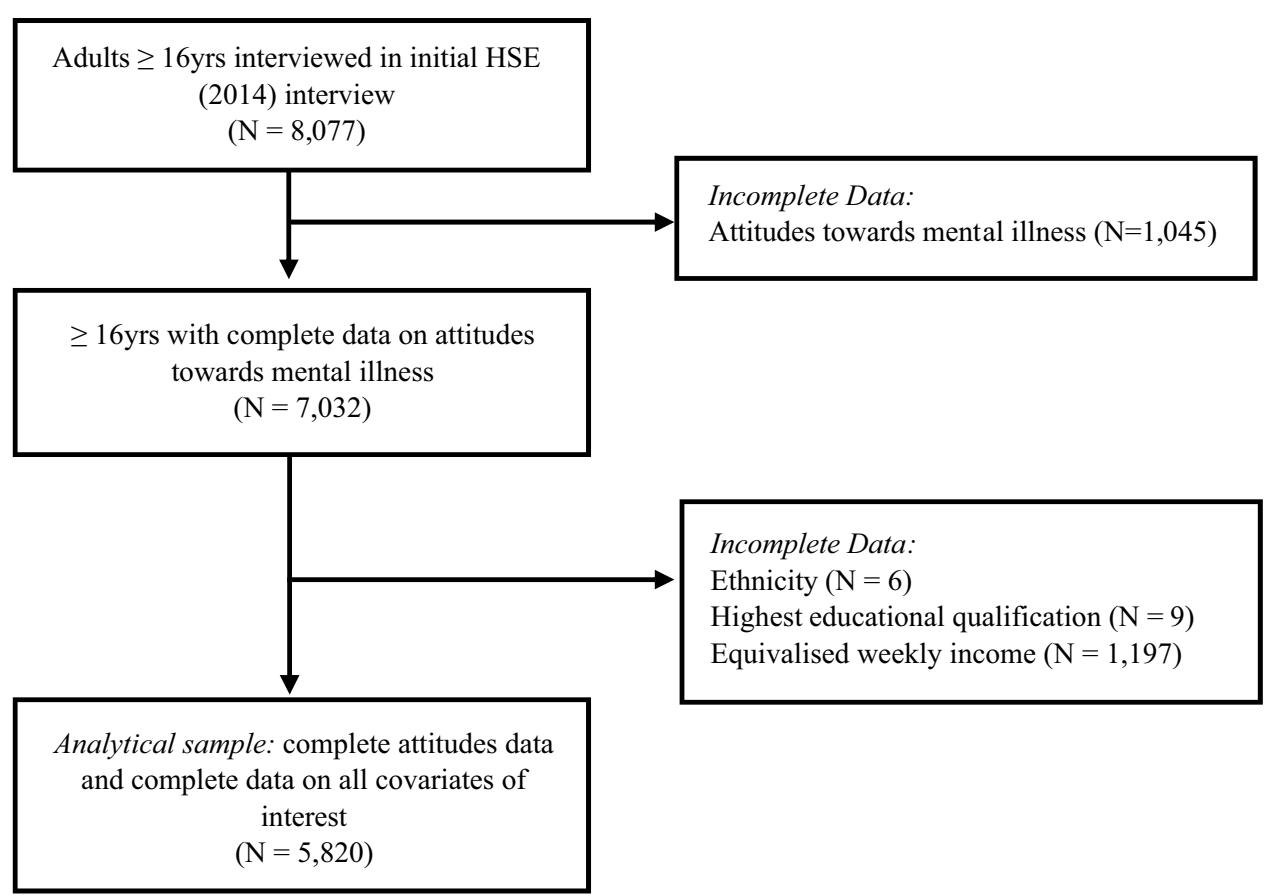


Table 1 Participant characteristics $(N=5820)$

\begin{tabular}{|c|c|}
\hline & $N(\%)$ \\
\hline \multicolumn{2}{|l|}{ Age } \\
\hline $16-24$ & $526(9.0)$ \\
\hline $25-34$ & $848(14.6)$ \\
\hline $35-44$ & $1079(18.4)$ \\
\hline $45-54$ & $1109(19.1)$ \\
\hline $55-64$ & $892(15.3)$ \\
\hline $65-74$ & $873(15.0)$ \\
\hline $75+$ & $493(8.5)$ \\
\hline \multicolumn{2}{|l|}{ Sex } \\
\hline Male & $2596(44.6)$ \\
\hline Female & $3224(55.4)$ \\
\hline \multicolumn{2}{|l|}{ Ethnicity } \\
\hline White & $5311(91.3)$ \\
\hline Black & $126(2.2)$ \\
\hline Asian & $273(4.7)$ \\
\hline Mixed/other & $110(1.9)$ \\
\hline \multicolumn{2}{|l|}{ Highest educational qualification } \\
\hline No qualifications & $1145(19.7)$ \\
\hline Post-16 qualifications such as GCSEs & $1443(24.6)$ \\
\hline Post-18 qualifications (below degree) such as A Levels & $1609(27.7)$ \\
\hline Degree level or equivalent & $1633(28.1)$ \\
\hline \multicolumn{2}{|l|}{ Equivalised weekly income } \\
\hline$£ 0-£ 233$ & $970(16.7)$ \\
\hline$£ 233-£ 369$ & $871(15.0)$ \\
\hline$£ 369-£ 532$ & $1241(21.3)$ \\
\hline$£ 532-£ 852$ & $1331(22.9)$ \\
\hline$£ 852+$ & $1407(24.2)$ \\
\hline \multicolumn{2}{|l|}{ Deprivation quintile } \\
\hline Least deprivation & $1596(22.7)$ \\
\hline Lower middle deprivation & $1432(20.4)$ \\
\hline Middle deprivation & $1378(19.6)$ \\
\hline Upper middle deprivation & $1348(19.2)$ \\
\hline Most deprivation & $1263(18.0)$ \\
\hline All statistics are number $(N)$ and percentage $(\%)$ & \\
\hline
\end{tabular}

although the magnitude of this relationship was again reduced (Table 3 ).

After further adjustment for ethnicity and weekly income, there was no evidence that participants living in the most deprived areas of England have worse overall attitudes towards mental illness than those residing in the least deprived areas (adjusted difference $=-0.1$ points, 95\% CI -1.3 to $1.2 ; P=0.931)$. This final model, controlling for age, sex, education level, ethnicity and weekly income, found no evidence of an association $\left(P_{\text {global }}=0.086\right)$, or of a trend $\left(P_{\text {trend }}=0.553\right)$, and model estimates were close to zero (Table 3 ).

In the final model, the majority of the variance in attitudes was between individuals, with $76.7 \%$ of the variance at the individual level, $23.3 \%$ at the household and $0.0 \%$ at the arealevel. A likelihood ratio (LR) test comparing models with and without a random effect of local area found no evidence that accounting for clustering by area provides a better fit to the data $(P>0.999)$.

There was no indication that the association between small area deprivation and overall attitudes towards mental health was explained by employment status or familiarity with mental illness (Online Resource 2), despite both being associated with attitudes (Table 2).

\section{Subscales of the modified CAMI}

The unadjusted analysis found strong evidence that individuals living in the most deprived areas in England have less positive attitudes reflecting views of prejudice and exclusion than those residing in the least deprived areas (estimated difference $=-4.9$ points; $95 \% \mathrm{CI}-6.5$ to $-3.3 ; P<0.001$ ). There was strong evidence from the unadjusted model for an overall association $\left(P_{\text {global }}<0.001\right)$, and for an overall trend, whereby higher levels of deprivation are associated with worse attitudes $\left(P_{\text {trend }}<0.001\right)$. This pattern of results remained after adjusting for age and sex. However, after further adjustment for education level, ethnicity and weekly income there was no evidence of differences in attitudes towards mental health for different levels of local deprivation $\left(P_{\text {global }}=0.134\right)$ (Table 3$)$.

There was likewise strong evidence that individuals residing in the most deprived areas in England hold less tolerant and supportive views towards mental illness than those from the least deprived areas (estimated difference $=-2.1$ points; $95 \% \mathrm{CI}-3.5$ to $-0.7 ; P=0.002)$, with strong evidence again for an overall association $\left(P_{\text {global }}=0.004\right)$, and trend $\left(P_{\text {trend }}=0.003\right)$. Controlling for age and sex altered these results slightly. After further adjustment for education level, no evidence remained for an overall association $\left(P_{\text {global }}=0.292\right)$ and model estimates were close to zero (Table 3).

In the final model, $79.9 \%$ of the variance in attitudes of prejudice and exclusion was found at the individual level, $20.1 \%$ at the household and $0.0 \%$ at the area-level. Similarly, $80.6 \%$ of the variance in attitudes of tolerance and support was found at the individual level, $19.4 \%$ at the household and $0.0 \%$ at the area level. LR tests comparing models with and without a random effect of area found no evidence that the addition of local area provides a better fit to the data for attitudes relating to either.

\section{Discussion}

In this study, findings from unadjusted models suggest that small area (LSOA) deprivation is associated with individual attitudes towards mental illness, with greater area 
Table 2 Estimated mean differences in attitudes towards mental illness for different levels of individual-level variables

\begin{tabular}{|c|c|c|c|c|c|c|}
\hline \multirow[t]{2}{*}{ Outcome } & \multicolumn{2}{|l|}{ Overall attitudes } & \multicolumn{2}{|c|}{ Attitudes of prejudice and exclusion } & \multicolumn{2}{|c|}{ Attitudes of tolerance and support } \\
\hline & $\begin{array}{l}\text { Estimated difference (95\% } \\
\mathrm{CI})\end{array}$ & $P$ value & $\begin{array}{l}\text { Estimated difference }(95 \% \\
\text { CI) }\end{array}$ & $P$ value & $\begin{array}{l}\text { Estimated difference }(95 \% \\
\text { CI) }\end{array}$ & $P$ value \\
\hline \multicolumn{7}{|l|}{ Age } \\
\hline $16-24$ (ref) & - & - & - & - & - & - \\
\hline $25-34$ & $3.0(1.4-4.6)$ & $<0.001$ & $1.6(-0.3$ to 3.6$)$ & 0.102 & $4.3(2.6-6.1)$ & $<0.001$ \\
\hline $35-44$ & $4.9(3.4-6.4)$ & $<0.001$ & $3.2(1.3-5.0)$ & 0.001 & $6.6(5.0-8.2)$ & $<0.001$ \\
\hline $45-54$ & $6.0(4.6-7.4)$ & $<0.001$ & $4.8(3.0-6.6)$ & $<0.001$ & $7.3(5.7-8.9)$ & $<0.001$ \\
\hline $55-64$ & $5.7(4.2-7.3)$ & $<0.001$ & $3.0(1.0-4.9)$ & 0.003 & $8.6(6.9-10.3)$ & $<0.001$ \\
\hline $65-74$ & $2.8(1.3-4.4)$ & $<0.001$ & $-1.7(-3.6$ to 0.3$)$ & 0.099 & $7.3(5.6-9.1)$ & $<0.001$ \\
\hline $75+$ & $0.1(-1.7$ to 1.8$)$ & 0.948 & $-7.7(-9.9$ to -5.4$)$ & $<0.001$ & $7.8(5.8-9.7)$ & $<0.001$ \\
\hline \multicolumn{7}{|l|}{ Sex } \\
\hline Male (ref) & - & - & - & - & - & - \\
\hline Female & $4.1(3.4-4.7)$ & $<0.001$ & $5.6(4.7-6.4)$ & $<0.001$ & $2.5(1.8-3.3)$ & $<0.001$ \\
\hline \multicolumn{7}{|l|}{ Ethnicity } \\
\hline White (ref) & - & - & - & - & - & - \\
\hline Black & $-6.1(-8.8$ to -3.5$)$ & $<0.001$ & $-9.1(-12.4$ to -5.8$)$ & $<0.001$ & $-3.2(-6.1$ to -0.3$)$ & 0.031 \\
\hline Asian & $-10.4(-12.3$ to -8.6$)$ & $<0.001$ & $-14.2(-16.6$ to -11.9$)$ & $<0.001$ & $-6.8(-8.8$ to -4.7$)$ & $<0.001$ \\
\hline Mixed/other & $-5.5(-8.3$ to -2.3$)$ & $<0.001$ & $-4.3(-7.9$ to -0.8$)$ & 0.016 & $-6.5(-9.6$ to -3.5$)$ & $<0.001$ \\
\hline \multicolumn{7}{|c|}{ Highest educational qualification } \\
\hline No qualifications (ref) & - & - & - & - & - & - \\
\hline $\begin{array}{l}\text { Post-16 qualifications } \\
\text { such as GCSEs }\end{array}$ & $3.0(1.9-4.1)$ & $<0.001$ & $6.2(4.8-7.6)$ & $<0.001$ & $-0.1(-1.3$ to 1.1$)$ & 0.853 \\
\hline $\begin{array}{l}\text { Post-18 qualifications } \\
\text { such as A Levels }\end{array}$ & $5.0(3.9-6.1)$ & $<0.001$ & $8.9(7.5-10.2)$ & $<0.001$ & $1.2(0.0-2.4)$ & 0.044 \\
\hline Degree level or equivalent & $8.0(6.9-9.1)$ & $<0.001$ & $12.1(10.7-13.5)$ & $<0.001$ & $4.1(2.9-5.3)$ & $<0.001$ \\
\hline \multicolumn{7}{|c|}{ Equivalised weekly income } \\
\hline$£ 0-£ 233$ (ref) & - & - & - & - & - & - \\
\hline$£ 233-£ 369$ & $1.0(-0.5$ to 2.4$)$ & 0.190 & $1.0(-0.8$ to 2.8$)$ & 0.268 & $0.9(-0.6$ to 2.5$)$ & 0.239 \\
\hline$£ 369-£ 532$ & $2.4(1.1-3.7)$ & $<0.001$ & $2.8(1.1-4.4)$ & 0.001 & $2.0(0.6-3.4)$ & 0.006 \\
\hline$£ 532-£ 852$ & $4.4(3.1-5.6)$ & $<0.001$ & $6.5(4.9-8.1)$ & $<0.001$ & $2.2(0.8-3.6)$ & 0.002 \\
\hline$£ 852+$ & $6.0(4.8-7.3)$ & $<0.001$ & $7.8(6.3-9.5)$ & $<0.001$ & $4.2(2.8-5.6)$ & $<0.001$ \\
\hline \multicolumn{7}{|c|}{ Closest person with mental illness $N=4227$} \\
\hline Self (ref) & - & - & - & - & - & - \\
\hline Immediate family/partner & $0.3(-1.8$ to 2.4$)$ & 0.786 & $0.3(-2.3$ to 2.9$)$ & 0.825 & $0.5(-1.9$ to 2.8$)$ & 0.699 \\
\hline Other family or friend & $-1.7(-3.9$ to 0.5$)$ & 0.125 & $-1.3(-4.1$ to 1.4$)$ & 0.347 & $-2.0(-4.5$ to 0.4$)$ & 0.109 \\
\hline $\begin{array}{l}\text { Acquaintance, colleague } \\
\text { or other }\end{array}$ & $-1.8(-4.4$ to 0.8$)$ & 0.168 & $-1.4(-4.7$ to 1.8$)$ & 0.393 & $-2.1(-5.0$ to 0.8$)$ & 0.155 \\
\hline Don't know anyone & $-8.4(-10.5$ to -6.3$)$ & $<0.001$ & $-10.3(-13.0$ to -7.6$)$ & $<0.001$ & $-6.5(-8.9$ to -4.1$)$ & $<0.001$ \\
\hline \multicolumn{7}{|c|}{ Employment status $N=5539$} \\
\hline $\begin{array}{l}\text { Employee not elsewhere } \\
\text { classified (ref) }\end{array}$ & - & - & - & - & - & - \\
\hline Self-employed & $-0.4(-1.5$ to 0.8$)$ & 0.555 & $-1.3(-2.8$ to 0.2$)$ & 0.084 & $0.7(-0.6$ to 2.0$)$ & 0.325 \\
\hline Manager & $1.3(-0.3$ to 2.9$)$ & 0.110 & $2.3(0.3-4.3)$ & 0.026 & $0.4(-1.4$ to 2.1$)$ & 0.659 \\
\hline Foreman or supervisor & $1.9(1.0-2.9)$ & $<0.001$ & $2.1(0.9-3.3)$ & $<0.001$ & $1.7(0.7-2.7)$ & 0.001 \\
\hline
\end{tabular}

Higher attitude scores indicate more positive views. 1593 participants had missing data on the closest person they know with a mental illness. 281 participants had missing data on employment status. All statistical models accounted for clustering within local area and household

deprivation associated with residents of these areas reporting less positive and, specifically, less tolerant and more prejudiced attitudes. This is in keeping with findings from previous research [8], however, the analyses in this earlier work did not control for differences in individual-level characteristics such as ethnicity and markers of SES and also did 
Table 3 Estimated mean differences in individual attitudes towards mental illness for different levels of local area deprivation

\begin{tabular}{|c|c|c|c|c|c|c|}
\hline \multirow[t]{2}{*}{ Outcome } & $\begin{array}{l}\text { Raw attitude } \\
\text { scores }\end{array}$ & Unadjusted models & $\begin{array}{l}\text { Adjusted for age } \\
\text { and sex }\end{array}$ & $\begin{array}{l}\text { Adjusted for age, } \\
\text { sex and education } \\
\text { level }\end{array}$ & $\begin{array}{l}\text { Adjusted for age, } \\
\text { sex, education } \\
\text { level and ethnicity }\end{array}$ & $\begin{array}{l}\text { Adjusted for age, } \\
\text { sex, education } \\
\text { level, ethnicity and } \\
\text { weekly income }\end{array}$ \\
\hline & Mean (SD) & $\begin{array}{l}\text { Estimated differ- } \\
\text { ence }(95 \% \mathrm{CI})\end{array}$ & $\begin{array}{l}\text { Estimated differ- } \\
\text { ence }(95 \% \mathrm{CI})\end{array}$ & $\begin{array}{l}\text { Estimated differ- } \\
\text { ence }(95 \% \mathrm{CI})\end{array}$ & $\begin{array}{l}\text { Estimated differ- } \\
\text { ence }(95 \% \mathrm{CI})\end{array}$ & $\begin{array}{l}\text { Estimated differ- } \\
\text { ence }(95 \% \mathrm{CI})\end{array}$ \\
\hline \multicolumn{7}{|l|}{ Overall attitudes } \\
\hline $\begin{array}{l}\text { Least deprivation } \\
\text { (ref) }\end{array}$ & $75.8(14.3)$ & - & - & - & - & - \\
\hline $\begin{array}{l}\text { Lower middle } \\
\text { deprivation }\end{array}$ & 74.5 (14.6) & $\begin{array}{l}-1.3(-2.6 \text { to } \\
-0.1)\end{array}$ & $\begin{array}{l}-1.3(-2.5 \text { to } \\
-0.1)\end{array}$ & $-1.1(-2.3$ to 0.1$)$ & $-1.1(-2.2$ to 0.1$)$ & $-1.0(-2.1$ to 0.2$)$ \\
\hline $\begin{array}{l}\text { Middle depriva- } \\
\text { tion }\end{array}$ & $75.4(14.4)$ & $-0.4(-1.6$ to 0.9$)$ & $-0.3(-1.5$ to 1.0$)$ & $0.5(-0.7$ to 1.7$)$ & $0.5(-0.7$ to 1.7$)$ & $0.8(-0.4$ to 2.0$)$ \\
\hline $\begin{array}{l}\text { Upper middle } \\
\text { deprivation }\end{array}$ & $73.6(14.6)$ & $\begin{array}{l}-2.2(-3.5 \text { to } \\
-0.9)\end{array}$ & $\begin{array}{l}-2.1(-3.3 \text { to } \\
-0.8)\end{array}$ & $-1.0(-2.2$ to 0.3$)$ & $-0.3(-1.5$ to 0.8$)$ & $0.0(-1.2$ to 1.2$)$ \\
\hline Most deprivation & $72.2(14.7)$ & $\begin{array}{l}-3.5(-4.8 \text { to } \\
-2.2)\end{array}$ & $\begin{array}{l}-3.4(-4.6 \text { to } \\
-2.1)\end{array}$ & $\begin{array}{l}-1.5(-2.8 \text { to } \\
-0.3)\end{array}$ & $-0.7(-1.9$ to 0.6$)$ & $-0.1(-1.3$ to 1.2$)$ \\
\hline$P_{\text {global }}^{\mathrm{a}}$ & - & $<0.001$ & $<0.001$ & 0.012 & 0.100 & 0.086 \\
\hline$P_{\text {trend }}^{\mathrm{b}}$ & - & $<0.001$ & $<0.001$ & 0.005 & 0.679 & 0.553 \\
\hline \multicolumn{7}{|c|}{ Attitudes of prejudice and exclusion } \\
\hline $\begin{array}{l}\text { Least deprivation } \\
\text { (ref) }\end{array}$ & $78.8(17.7)$ & - & - & - & - & - \\
\hline $\begin{array}{l}\text { Lower middle } \\
\text { deprivation }\end{array}$ & $77.4(17.9)$ & $-1.5(-3.1$ to 0.0$)$ & $-1.4(-2.9$ to 0.1$)$ & $-1.1(-2.6$ to 0.3$)$ & $-1.1(-2.6$ to 0.3$)$ & $-1.0(-2.4$ to 0.4$)$ \\
\hline $\begin{array}{l}\text { Middle depriva- } \\
\text { tion }\end{array}$ & $78.1(18.2)$ & $-0.6(-2.2$ to 0.9$)$ & $-0.5(-2.0$ to 1.1$)$ & 0.5 ( -1.1 to 2.0$)$ & $0.5(-1.0$ to 1.9$)$ & $0.8(-0.6$ to 2.3$)$ \\
\hline $\begin{array}{l}\text { Upper middle } \\
\text { deprivation }\end{array}$ & $76.0(18.5)$ & $\begin{array}{l}-2.8(-4.4 \text { to } \\
-1.2)\end{array}$ & $\begin{array}{l}-3.0(-4.6 \text { to } \\
-1.5)\end{array}$ & $\begin{array}{l}-1.6(-3.1 \text { to } \\
-0.1)\end{array}$ & $-0.7(-2.2$ to 0.7$)$ & $-0.3(-1.8$ to 1.2$)$ \\
\hline Most deprivation & $73.8(19.2)$ & $\begin{array}{l}-4.9(-6.5 \text { to } \\
-3.3)\end{array}$ & $\begin{array}{l}-5.1(-6.7 \text { to } \\
-3.5)\end{array}$ & $\begin{array}{l}-2.7(-4.3 \text { to } \\
-1.1)\end{array}$ & $-1.5(-3.1$ to 0.0$)$ & $-0.8(-2.4$ to 0.8$)$ \\
\hline$P_{\text {global }}$ & - & $<0.001$ & $<0.001$ & 0.001 & 0.060 & 0.134 \\
\hline$P_{\text {trend }}$ & - & $<0.001$ & $<0.001$ & 0.002 & 0.142 & 0.680 \\
\hline \multicolumn{7}{|c|}{ Attitudes of tolerance and support } \\
\hline $\begin{array}{l}\text { Least deprivation } \\
\text { (ref) }\end{array}$ & $73.3(15.0)$ & - & - & - & - & - \\
\hline $\begin{array}{l}\text { Lower middle } \\
\text { deprivation }\end{array}$ & $72.3(15.8)$ & $-1.1(-2.4$ to 0.2$)$ & $-1.2(-2.5$ to 0.1$)$ & $-1.0(-2.3$ to 0.3$)$ & - & - \\
\hline $\begin{array}{l}\text { Middle depriva- } \\
\text { tion }\end{array}$ & $73.0(15.2)$ & $-0.1(-1.5$ to 1.3$)$ & $-0.1(-1.4$ to 1.3$)$ & $0.5(-0.9$ to 1.8$)$ & - & - \\
\hline $\begin{array}{l}\text { Upper middle } \\
\text { deprivation }\end{array}$ & $71.8(17.1)$ & $\begin{array}{l}-1.6(-3.0 \text { to } \\
-0.3)\end{array}$ & $-1.1(-2.5$ to 0.2$)$ & $-0.3(-1.7$ to 1.0$)$ & - & - \\
\hline Most deprivation & $70.6(17.4)$ & $\begin{array}{l}-2.1(-3.5 \text { to } \\
-0.7)\end{array}$ & $\begin{array}{l}-1.7(-3.0 \text { to } \\
-0.3)\end{array}$ & $-0.3(-1.7$ to 1.1$)$ & - & - \\
\hline$P_{\text {global }}$ & - & 0.004 & 0.066 & 0.292 & - & - \\
\hline$P_{\text {trend }}$ & - & 0.003 & 0.037 & 0.964 & - & - \\
\hline
\end{tabular}

${ }^{\text {a }} P_{\text {global }}$ indicates the strength of evidence for overall differences in attitudes to mental health for different levels of local area deprivation

${ }^{\mathrm{b}} P_{\text {trend }}$ indicates the strength of evidence for a dose-response relationship between area deprivation and attitudes. Higher attitude scores indicate more positive views. All statistical models accounted for clustering within local area and household

not account for the possible clustering of attitudes within households and areas.

Our final multilevel model for overall attitudes towards mental illness suggests that there is no association between small area deprivation and attitudes after adjusting for age, sex, education level, ethnicity and weekly income, with educational level appearing to explain much of the unadjusted association. We found a similar pattern of results for attitudes towards mental illness reflecting views of: (1) prejudice and exclusion and (2) tolerance and support 
for community care, with the exception that ethnicity and weekly income do not appear to explain the unadjusted relationship between area deprivation and attitudes of tolerance and support. Individual-level factors, therefore, seem to play a greater role in determining attitudes towards mental illness.

This study found no evidence to suggest that employment status or familiarity with mental illness explain the relationship between small area-level deprivation and attitudes towards mental illness, despite both being associated with attitudes in univariable analyses. The latter findings are supported by previous research, which suggests that lower levels of employment are associated with worse attitudes and participants who are more familiar with mental health problems report more positive attitudes, in keeping with Allport's contact hypothesis whereby more positive attitudes form through contact with stigmatised groups [7, 8, 12, 13, 23]. Whilst there is evidence in the literature to suggest area deprivation is associated with employment status [24], there is no evidence that individuals who are more familiar with mental illness reside in less deprived areas. Our findings suggest that, whilst both variables predict attitudes towards mental illness, neither can explain the observed association between area deprivation and attitudes.

It is currently unclear why educational level appears to explain the majority of the effect that small area deprivation has on individual attitudes towards mental illness. Firstly, education level may confound the relationship. It seems plausible that lower educational attainment in adolescence may leave young people with fewer qualifications and skills which in turn affects future income [25], causing these individuals to migrate to more affordable areas with greater levels of deprivation. In turn, individuals who complete more years of education may have more knowledge of, and familiarity with, mental illness [26]. This could, in turn, lead to less prejudiced and more tolerant views; ultimately resulting in less stigma and discrimination.

That said, the relationships between area deprivation, educational attainment and attitudes are more likely to be multi-directional and considerably more complex. Findings from multilevel analyses of Scottish survey and area data suggest greater deprivation in the home neighbourhood is associated with subsequently lower educational attainment [27]. Educational attainment, therefore, could be on the causal pathway whereby greater neighbourhood deprivation leads to poorer educational attainment, in turn leading to less positive attitudes.

This study also presents evidence suggesting participants from ethnic minority groups report the least positive attitudes and ethnicity may partially explain the association between small area deprivation and attitudes towards mental illness. However, how ethnicity is related is unclear and there is a need to consider how stigma-related factors such as area deprivation and ethnicity relate, intersect and mutually reinforce each other in different groups [28]. By acknowledging that stigma expressed in ethnic minority populations may be complicated by the experiences of being a cultural minority and/or experiencing racial discrimination, and exacerbated by those who value resilience in the face of discrimination [29], we may be able to better understand the factors contributing to stigmatising attitudes.

One way in which stigma-related factors may relate to influence attitudes may be by exerting their effects on different structural levels [30]. The effect of being deprived at an individual level, manifesting via markers such as educational attainment, may influence attitudes in a way that is distinct from the effect of living in a deprived area. This distinction between individual-level (compositional) and area or household-level (contextual) effects is regularly explored in health research and has a place in stigma research [30]. This study shows that associations between area deprivation and attitudes towards mental illness disappear when adjusting for individual-level variables. This suggests a compositional effect on attitudes rather than a contextual one [30]. Interestingly, it is important to note this study found that $23.3 \%$ of the variation in overall attitudes towards mental illness can be explained by household-level factors. This suggests a further contextual level of the household (or family) is an important determinant of stigmatising attitudes at the individual level. This may be because we seek companionship with those holding similar beliefs [31] or pressures to conform to group attitudes lead to common beliefs within a household [32]. It is important that future work considers how parental attitudes towards mental illness may shape those of their children, creating intra-generational similarities that permeate several households over time and reinforce mental health stigma [33].

It is beyond the scope of this study to fully deconstruct the relationship between the deprivation level of the local area in which individuals reside and their attitudes towards mental illness. However, we have demonstrated that certain individual-level factors, in particular education level, may explain the apparent association. Interestingly, different individual-level variables explain the association between area-level deprivation and attitudes reflecting: (1) prejudice and exclusion and (2) tolerance and support for community care, although the mechanisms for this are unclear.

With instant messaging platforms such as email and Facebook, it may be unsurprising that our final fully adjusted models found little or no residual area-level variation in attitudes towards mental illness. Internet and social media use has become profoundly integral to our everyday lives-in $2018,90 \%$ of UK adults were recent internet users and a large proportion of adults used the internet for social networking (64.5\%) and emailing (84\%) [34]. With respect to our findings, internet and social media use could be dissipating the influence that small area deprivation has on 
individual attitudes towards mental illness. Evidence suggests communities may be shifting to online forums, augmenting social capital and making it more geographically dispersed [35]. Hence, individual attitudes may no longer be influenced by geographical factors such as area deprivation, but rather by the types of social media groups, communities and online content we engage with. Our LR tests suggest that, after adjusting for education level, ethnicity and weekly income, our findings would have been observed regardless of the inclusion of an area-level in the multilevel models.

\section{Strengths and limitations}

A key strength of this study is that it presents novel findings, adding to the mental health stigma literature. We have also used methodologically superior statistically techniques compared to previous studies and reports. Using multilevel models to account for any clustering of attitudes within households and small geographical areas, we have been able to explain the observed association between area deprivation and attitudes towards mental illness previously reported by NatCen [8]. We have also accounted for the effects of various individual characteristics.

On the other hand, this study is not without limitations. Firstly, HSE is cross-sectional, failing to capture how fluctuations in area deprivation over time may be associated with individual attitudes and limiting our ability to draw causal inferences. For example, as discussed, education may be on the causal pathway between area deprivation and attitudes towards mental illness. The same may be true for weekly income. If this is the case, adjusting for these may lead to overadjustment biases [36, 37]. A second limitation is the sample used. $90.3 \%$ of the sample is White, whilst only $2.3 \%$ are Black, $5.6 \%$ Asian and $1.9 \%$ classified as mixed/other. Although these proportions are roughly similar to the ethnic breakdown of England [38], the number of participants in the latter categories may affect the accuracy of model estimates [39]. In addition, the final analysis is unweighted and therefore does not take into account nonresponse. Although estimates weighted by design weights are often less precise than unweighted estimates [40], there is a risk of non-response bias-high area-level deprivation [41] and low educational attainment [42] have both been shown to be associated with survey non-response. However, since this study was interested in estimating the association between area-level deprivation and attitudes towards mental illness, rather than estimating prevalence, then adjusting for non-response is not essential. Several previous studies have used similar data, aims and unweighted analyses to reach their conclusions [43-45]. Finally, this study may not include information on all variables that affect the association between area deprivation and attitudes. For example, local differences in news coverage of mental illness, which were not captured in this study, are associated with stigmatising attitudes of area residents and could confound the relationship [46].

\section{Implications and conclusions}

Our results suggest that individual-level variables may explain the previously observed relationship between small area deprivation and attitudes towards mental illness [8]. In particular, education level may be key. This study shows that the magnitude of the association is greatly reduced when controlling for education level-greater area-level deprivation is no longer associated with strikingly worse individual attitudes. This contrasts with previous findings [8].

Based on the findings of this present study, it is important that future research exploring the causes of negative and stigmatising attitudes towards mental illness sufficiently explore individual-level differences in education, ethnicity and income, as well as differences in other household-level characteristics and family contexts. This is key if we want to obtain a comprehensive understanding of the factors that contribute to stigma. Further work should also explore why ethnicity is an important factor affecting the relationship between small area deprivation and attitudes of prejudice and exclusion, but not attitudes of tolerance and support.

By unpicking these relationships, local governments and other organisations could better target public health initiatives aiming to reduce stigmatising attitudes. This could allow a larger proportion of resources to be focused on groups with the least positive attitudes, thus improving the effectiveness of such initiatives. Ultimately, this could improve attitudes towards mental illness and work towards eradicating the experiences of stigma that individuals with mental disorders can face.

Acknowledgements With thanks to Anne Conolly at the National Centre for Social Research (NatCen) for assistance with access to and advice on use of the data, and to Rachel Craig and Sally Bridges at NatCen for their work on the 12 item version of the CAMI for HSE 2014. Claire Henderson, King' College London was supported by the Maudsley Charity and the National Institute for Health Research (NIHR) Collaboration for Leadership in Applied Health Research and Care South London (NIHR CLAHRC South London) at King's College Hospital NHS Foundation Trust. The views expressed are those of the author[s] and not necessarily those of the NIHR or the Department of Health and Social Care.

\section{Compliance with ethical standards}

Conflict of interest The authors declare that they have no conflict of interests.

Ethical standards The manuscript does not contain clinical studies or patient data. 
Open Access This article is distributed under the terms of the Creative Commons Attribution 4.0 International License (http://creativeco mmons.org/licenses/by/4.0/), which permits unrestricted use, distribution, and reproduction in any medium, provided you give appropriate credit to the original author(s) and the source, provide a link to the Creative Commons license, and indicate if changes were made.

\section{References}

1. McManus S., Meltzer H., Brugha TS, Bebbington PE, Jenkins R (2009) Adult psychiatric morbidity in England, 2007: results of a household survey. The NHS Information Centre for Health and Social care. https://digital.nhs.uk/data-and-information/ publications/statistical/adult-psychiatric-morbidity-survey/adult -psychiatric-morbidity-survey-survey-of-mental-health-andwellbeing-england-2014\#resources Accessed 20 Nov 2018

2. Curtice, J \& Ormston, R. (2015). British social attitudes 33. http://www.bsa.natcen.ac.uk/media/39109/phe-bsa-2015-attit udes-to-mental-health.pdf. Accessed 20 Nov 2018

3. Clement S, Schauman O, Graham T, Maggioni F, Evans-Lacko S, Bezborodovs N, Thornicroft G (2015) What is the impact of mental health-related stigma on help-seeking? A systematic review of quantitative and qualitative studies. Psychol Med 45(1):11-27. https://doi.org/10.1017/S0033291714000129

4. Sanderson K, Andrews G (2006) Common mental disorders in the workforce: recent findings from descriptive and social epidemiology. Can J Psychiatry 51(2):63-75. https://doi. org/10.1177/070674370605100202

5. Thornicroft G, Rose D, Kassam A, Sartorius N (2007) Stigma: ignorance, prejudice or discrimination? Br J Psychiatry 190(3):192-193. https://doi.org/10.1192/bjp.bp.106.025791

6. Crocker J, Major B, Steele C (1998) Social stigma. In: Gilbert D, Fiske ST, Lindzey G (eds) The handbook of social psychology, vol 2, 4th edn. McGraw- Hill, New York, pp 504-553

7. Henderson C, Robinson E, Evans-Lacko S, Corker E, RebolloMesa I, Rose D, Thornicroft G (2016) Public knowledge, attitudes, social distance and reported contact regarding people with mental illness 2009-2015. Acta Psychiatr Scand 134(S446):23-33. https://doi.org/10.1111/acps.12607

8. Ilic N, Henderson H, Henderson C, Evans-Lacko S, Thornicroft G (2014) Chapter 3 attitudes towards mental illness HSE 2014. https://files.digital.nhs.uk/publicationimport/pub19xxx/pub19 295/hse2014-ch3-mh-att.pdf. Accessed 20 Nov 2018

9. Hansson L, Stjernswärd S, Svensson B (2016) Changes in attitudes, intended behaviour, and mental health literacy in the Swedish population 2009-2014: an evaluation of a national antistigma programme. Acta Psychiatr Scand 134:71-79. https ://doi.org/10.1111/acps.12609

10. Chandra A, Minkovitz CS (2006) Stigma starts early: gender differences in teen willingness to use mental health services. J Adolesc Health 38:754. e1-754. e8. https://doi.org/10.1016/j. jadohealth.2005.08.011

11. Angermeyer MC, Beck M, Matschinger H (2003) Determinants of the public's preference for social distance from people with schizophrenia. Can J Psychiatry 48:663-668. https://doi. org/10.1177/070674370304801004

12. Boyd JE, Katz EP, Link BG, Phelan JC (2010) The relationship of multiple aspects of stigma and personal contact with someone hospitalized for mental illness, in a nationally representative sample. Soc Psychiatry Psychiatr Epidemiol 45:1063-1070. https://doi.org/10.1007/s00127-009-0147-9

13. Papadopoulos C, Leavey G, Vincent C (2002) Factors influencing stigma. Soc Psychiatry Psychiatr Epidemiol 37(9):430-434. https://doi.org/10.1007/s00127-002-0560-9
14. McLennan D, Barnes H, Noble M et al. (2011). The english indices of deprivation 2010. https://assets.publishing.servi ce.gov.uk/government/uploads/system/uploads/attachment _data/file/6320/1870718.pdf Accessed 20 Nov 2018

15. Guerin B (1994) Attitudes and beliefs as verbal behavior. Behav Anal 17(1):155-163. https://doi.org/10.1007/BF03392661

16. Robinson EJ, Henderson C (2018) Public knowledge, attitudes, social distance and reporting contact with people with mental illness 2009-2017. Psychol Med 20:1-10. https://doi. org/10.1017/S0033291718003677

17. NatCen Social Research, University College London, Department of Epidemiology and Public Health (2018) Health Survey for England, 2014. [data collection]. 3rd Edition. UK Data Service. SN: 7919. https://doi.org/10.5255/UKDA-SN-7919-3

18. Bridges, S., Darton, R., Evans-Lacko,S., et al. (2014). Health Survey for England (2014) Methods and documentation. https:// files.digital.nhs.uk/publicationimport/pub19xxx/pub19295/hse20 14-methods-and-docs.pdf Accessed 21 Nov 2018

19. Taylor M, Dear M (1971) Scaling community attitudes toward the mentally ill. Schizphrenia Bull 7(2):225-240

20. Nunnaly J (1978) Psychometric theory. McGraw-Hill, New York

21. Dibben C, Atherton I, Cox M, Watson V, Ryan M, Sutton M (2007) Investigating the impact of changing the weights that underpin the index of multiple deprivation 2004. London: Department for Communities and Local Government. https://webarchive .nationalarchives.gov.uk/20100407225738/http://www.commu nities.gov.uk/documents/communities/pdf/323211.pdf. Accessed 20 Nov 2018

22. Time to Change (2014). National attitudes to mental illness 2014 research report. https://www.time-to-change.org.uk/sites/defau 1t/files/Attitudes_to_mental_illness_2014_report_final_0.pdf Accessed 20 Nov 2018

23. Allport G (1954) The nature of prejudice. Addison-Wesley Publishing Company Inc, Reading

24. McCulloch A (2001) Ward-level deprivation and individual social and economic outcomes in the British household panel study. Environ Plan A 33(4):667-684. https://doi.org/10.1068/a33205

25. Jimerson SR (1999) On the failure of failure: examining the association between early grade retention and education and employment outcomes during late adolescence. J Sch Psychol 37(3):243272. https://doi.org/10.1016/S0022-4405(99)00005-9

26. Holmes EP, Corrigan PW, Williams P, Canar J, Kubiak M (1999) Changing public attitudes about schizophrenia. Schizophr Bull 25:447-456

27. Garner CL, Raudenbush SW (1991) Neighborhood effects on educational attainment: A multilevel analysis. Sociol Educ 64(4):251-262. https://doi.org/10.2307/2112706

28. Hancock AM (2007) When multiplication doesn't equal quick addition: examining intersectionality as a research paradigm. Perspect Politics 5(1):63-79. https://doi.org/10.1017/S153759270 7070065

29. Shefer G, Rose D, Nellums L, Thornicroft G, Henderson C, Evans-Lacko S (2013) 'Our community is the worst': the influence of cultural beliefs on stigma, relationships with family and help-seeking in three ethnic communities in London. Int J Soc Psychiatry 59(6):535-544. https://doi.org/10.1177/0020764012 443759

30. Duncan C, Jones K, Moon G (1998) Context, composition and heterogeneity: using multilevel models in health research. Soc Sci Med 46(1):97-117. https://doi.org/10.1016/S0277-9536(97)00148 $-2$

31. Bryne D (1971) The attraction paradigm. The Academic Press, New York

32. Hardy KR (1957) Determinants of conformity and attitude change. J Abnorm Soc Psychol 54(3):289-294. https://doi.org/10.1037/ h0048374 
33. Sinclair S, Dunn E, Lowery B (2005) The relationship between parental racial attitudes and children's implicit prejudice. J Exp Soc Psychol 41(3):283-289. https://doi.org/10.1016/j. jesp.2004.06.003

34. The Office of National Statistics (2018). Internet access-households and individuals, Great Britain: 2018. https://www.ons.gov. uk/peoplepopulationandcommunity/householdcharacteristics/ homeinternetandsocialmediausage/bulletins/internetaccesshouseh oldsandindividuals/2018\#email-remains-the-most-common-inter net-activity. Accessed 20 Nov 2018

35. Quan-Haase A, Wellman B, Witte JC (2002) Capitalizing on the net: social contact, civic engagement, and sense of community. In: Wellman B, Haythornthwaite C (eds) The Internet in Everyday Life. Blackwell, Oxford, pp 291-324

36. Jager KJ, Zoccali C, Macleod A, Dekker FW (2008) Confounding: what it is and how to deal with it. Kidney Int 73(3):256-260. https ://doi.org/10.1038/sj.ki.5002650

37. Schisterman EF, Cole SR, Platt RW (2009) Overadjustment bias and unnecessary adjustment in epidemiologic studies. Epidemiol (Cambridge, Mass.) 20(4):488. https://doi.org/10.1097/ede.0b013 e3181a819a1

38. Office of National Statistics (2012). Ethnic breakdown of England and Wales. https://www.ons.gov.uk/peoplepopulationandcommun ity/culturalidentity/ethnicity/articles/ethnicityandnationalident ityinenglandandwales/2012-12-11 Accessed 20 Nov 2018

39. Maas CJ, Hox JJ (2005) Sufficient sample sizes for multilevel modeling. Methodology 1(3):86-92. https://doi. org/10.1027/1614-1881.1.3.86
40. Mansournia MA, Altman DG (2016) Inverse probability weighting. Bmj 352:i189. https://doi.org/10.1136/bmj.i189

41. Chaix B, Billaudeau N, Thomas F, Havard S, Evans D et al (2011) Neighborhood effects on health: correcting bias from neighborhood effects on participation. Epidemiology 22:18-26. https://doi. org/10.1097/EDE.0b013e3181fd2961

42. Tolonen H, Helakorpi S, Talala K, Helasoja V, Martelin T, Prättälä $\mathrm{R}$ (2006) 25-year trends and socio-demographic differences in response rates: finnish adult health behaviour survey. Eur J Epidemiol 21(6):409-415. https://doi.org/10.1007/s 10654-006-9019-8

43. Moon G, Aitken G, Taylor J, Twigg L (2017) Integrating national surveys to estimate small area variations in poor health and limiting long-term illness in Great Britain. BMJ Open 7(8):e016936. https://doi.org/10.1136/bmjopen-2017-016936

44. Das-Munshi J, Becares L, Dewey ME, Stansfeld SA, Prince MJ (2010) Understanding the effect of ethnic density on mental health: multi-level investigation of survey data from England. BMJ 341:c5367. https://doi.org/10.1136/bmj.c5367

45. Das-Munshi J, Bécares L, Boydell JE, Dewey ME, Morgan C, Stansfeld SA, Prince MJ (2012) Ethnic density as a buffer for psychotic experiences: findings from a national survey (EMPIRIC). Br J Psychiatry 201(4):282-290. https://doi.org/10.1192/bjp. bp. 111.102376

46. Thornicroft A, Goulden R, Shefer G, Rhydderch D, Rose D, Williams P, Thornicroft G, Henderson C (2013) Newspaper coverage of mental illness in England 2008-2011. Br J Psychiatry Suppl 55:s64-s69. https://doi.org/10.1192/bjp.bp.112.112920 